(c) American Dairy Science Association, 2007.

\title{
Detection of Quantitative Trait Loci Affecting Lameness and Leg Conformation Traits in Danish Holstein Cattle
}

\author{
A. J. Buitenhuis, ${ }^{\star 1}$ M. S. Lund, ${ }^{\star}$ J. R. Thomasen, ${ }^{*} \dagger$ B. Thomsen, ${ }^{*}$ V. Hunnicke Nielsen, ${ }^{*}$ \\ C. Bendixen, ${ }^{*}$ and B. Guldbrandtsen* \\ *Danish Institute of Agricultural Sciences, Department of Genetics and Biotechnology, PO Box 50, 8830 Tjele, Denmark \\ †Kvægavlsforeningen Dansire, Ebeltoftvej 16, Assentoft, 8900 Randers, Denmark
}

\begin{abstract}
Lameness is an important factor for culling animals. Strong legs and feet improve herd life of dairy cows. Therefore, many countries include leg and feet conformation traits in their breeding programs, often as early predictors of longevity. However, few countries directly measure lameness related traits to include these in a breeding program. Lameness indices in 3 different lactations and 5 leg conformation traits (rear legs side view, rear legs rear view, hock quality, bone quality, and foot angle) were measured on granddaughters of 19 Danish Holstein grandsires with 33 to 105 sons. A genome scan was performed to detect quantitative trait loci (QTL) based on the 29 autosomes using microsatellite markers. Data were analyzed across and within families for QTL affecting lameness and leg conformation traits. A regression method and a variance component method were used for QTL detection. Two QTL each for lameness in the first [Bos taurus autosome (BTA); BTA5, BTA26] and second (BTA19, BTA22) lactations were detected. For the 5 different leg conformation traits, 7 chromosome-wise significant QTL were detected across families for rear legs side view, 5 for rear legs rear view, 4 for hock quality, 4 for bone quality, and 1 for foot angle. For those chromosomes where a QTL associated with 2 different traits was detected (BTA1, BTA11, BTA15, BTA26, and BTA27), a multitrait-1-QTL model and a multitrait-2-QTL model were performed to characterize these QTL as single QTL with pleiotropic effects or distinct QTL.
\end{abstract}

Key words: dairy cattle, lameness, leg conformation, quantitative trait loci

\section{INTRODUCTION}

Mapping of QTL has mainly focused on production traits such as milk yield and milk composition (Boven-

Received March 20, 2006.

Accepted August 31, 2006.

${ }^{1}$ Corresponding author: bart.buitenhuis@agrsci.dk huis and Schrooten, 2002). However, the focus of selection in dairy cattle breeding is continually changing to put more weight on nonproduction traits such as health traits (Holmberg and Andersson-Eklund, 2004), behavioral traits (Schmutz et al., 2001), functional traits, and conformation traits like feet and legs (Schrooten et al., 2000; Kühn et al., 2003). Feet and leg problems in cattle are among the most common diseases in dairy cattle (Enting et al., 1997) and are the third most important reason for involuntary culling (15\%) in the United States after reproductive problems (26.7\%) and udder and mastitis problems (26.5\%; APHIS, 1996). A study on the cause of mortality in Danish dairy cows showed that locomotive disorders were the most frequently stated cause (25\%) of death, unassisted or by euthanasia (Thomsen et al., 2004).

Lameness due to claw disorders is a problem in modern cattle housing systems. Reducing lameness would be beneficial for the farmer because the lactational and lifetime production of the cow increases, whereas the costs decrease. Indirect selection using correlated leg conformation traits would be a possibility to reduce lameness in cattle because leg conformation traits are correlated with claw disorders (van der Waaij et al., 2005). However, even though body conformation traits describing feet and legs have been part of the breeding scene for decades, selection for these traits alone as practiced has not reduced lameness in a satisfactory way. Genetic parameters for claw disorders causing lameness have been estimated before (Smit et al., 1986; Boelling et al., 2001; van der Waaij et al., 2005), but usually the estimates have a low accuracy and the heritability does not exceed 0.15. In the Danish Holstein population the heritability for lameness is around 1 to 2\% (Pedersen Aamand, 2002).

The conformation trait feet and legs is recorded as different subtraits like rear legs rear view, rear legs side view, foot angle, hocks, and bone quality. The heritability of these traits ranges from 0.12 to 0.41 (Van Dorp et al., 1998; Pérez-Cabal and Alenda, 2002; Hiendleder et al., 2003). In the Danish Holstein population, the heritabilities of these traits range from 0.13 to 0.28 (Pedersen Aamand, 2002). Feet and legs is one of the 
most important traits determining productive life. If an animal has bad legs, this problem has a major effect on longevity but not on final profit (Pérez-Cabal and Alenda, 2002).

So far, selection for body conformation traits has been based on phenotypic and pedigree data only, using statistical methods partitioning the phenotype into continuously distributed additive genetic value and environmental contributions. Lameness has a low heritability and can often be measured accurately late in life. Leg conformation traits have a moderate heritability and could be used as an indicator trait for lameness. However, the observations also for leg conformation traits become available relatively late in life, at least after the first calving. Therefore, identification of QTL directly associated with lameness could help to more accurately select early in life those animals that are less prone to suffer lameness at a later age, whereas QTL for leg conformation traits could help to select those animals that have legs which are more robust to lameness (McDaniel, 1997). Previous studies from different countries have shown that one can detect QTL associated with feet and leg-related traits in Holstein cattle (Ashwell et al., 1998a,b, 2001, 2005; Schrooten et al., 2000; Hiendleder et al., 2003); however, results from studies reporting QTL for lameness have not been reported so far.

To increase the knowledge of the genetics of lameness and leg conformation traits, several claw disorders and diseases as well as different leg conformation traits were measured in the Danish Holstein cattle population. The aims of the study were to (1) detect QTL across the cattle genome influencing lameness and leg conformation traits and (2) characterize QTL for pleiotropy vs. multiple linked QTL when QTL for different traits were detected on the same chromosome. The genetic basis for QTL on the same chromosome is of interest when performing marker-assisted selection, especially when using conformation traits to indirectly select for decreased lameness.

\section{MATERIALS AND METHODS}

\section{Animals}

The study was based on a granddaughter design of 19 Danish Holstein sire families with 1,373 progeny tested sons. The number of sons per grandsire ranged from 33 to 105, with an average family size of 72.3 .

\section{Markers and Maps}

Markers and their positions were chosen from previously published maps (Barendse et al., 1997) and from the Web site of the Meat Animal Research Center (http://www.marc.usda.gov/genome/genome.html). All autosomes [Bos taurus chromosomes (BTA) 1 to 29] were covered in a whole genome scan. The genome was screened using 327 microsatellite markers with an average marker spacing of $7.97 \mathrm{cM}$. Marker genotypes were determined on an automated sequence analyzer (ABI, Perkin Elmer). Table 1 shows the markers used per chromosome.

\section{Phenotypic Data Lameness Traits}

Daughters of bulls were scored by veterinarians for heel erosion, interdigital dermatitis, claw trimming by veterinarian, interdigital necrobacillosis, interdigital skin hyperplasia, laminitis, arthritis, sole ulcer, pressure injuries, tenosynovitis of hooves, and other leg diseases in their first, second, and third lactations. If an animal was treated for one of the above-mentioned diseases, the phenotype was scored as positive and assigned a value of 1 , whereas healthy animals were considered negative and assigned a score of 0 . A lameness index was calculated for the first, second, and third lactations (Lameness1, Lameness2, and Lameness3) by means of a multitrait BLUP sire model (Danish Cattle Federation, 2003).

\section{Leg Conformation Traits}

Daughters of bulls were scored for leg conformation on location by trained inspectors. The 5 leg conformation traits scored were: rear legs side view, rear legs rear view, hock quality, bone quality, and foot angle. These traits were subjectively scored on an ordered categorical scale ranging from 1 to 9 . Estimated breeding values for leg conformation traits of sons based on phenotypes of their daughters were calculated using a single-trait BLUP animal model consistent with the Interbull procedure, but using only Danish recordings. These EBV were used as phenotypes in the QTL analysis. Detailed information about the definition of the traits and the calculation of the EBV can be found at http://www-interbull.slu.se/national_ges_info2/frame sida-ges.htm

\section{QTL Analysis}

The QTL mapping procedure was as follows. First, a within-family regression analysis was used to identify segregating sires. Second, a variance component method was used for an across family analysis using a single-trait single QTL model. If 2 traits showed a significant QTL on the same chromosome, the data were analyzed subsequently using a multitrait single QTL model and a multitrait multiQTL model.

Regression Analysis. The marker linkage phases in the grandsires were determined based on offspring 
Table 1. Distribution of the markers across the chromosomes, including chromosomal location in centimorgans in parentheses

\begin{tabular}{|c|c|c|}
\hline BTA $^{1}$ & Marker $^{2}$ & $\mathrm{NM}^{3}$ \\
\hline 1 & $\begin{array}{l}\text { AGLA17(0) BM6438(1.6) TGLA49(1.9) AR09(3.0) BMS4017(34.8) BMS4000(47.6) RM326(55.6) BMS4013(61.3) } \\
\text { INRA049(67.5) BMS4008(71.7) BM8246(76.2) BMS4031(77.7) TGLA130(98.2) BMS1789(100.9) CSSM019(108.3) } \\
\text { BM1824(108.6) UWCA46(113.2) BMS918(118.1) BMS4043(128.7) URB014(142.1) }\end{array}$ & 20 \\
\hline 3 & $\begin{array}{l}\text { INRA006(19.5) UWCA7(19.9) ILSTS096(29.7) FCGR1(35.0) BMS963(35.6) BL41(45.2) INRA003(59.3) BMS2790(62.4) } \\
\text { ILSTS029(64.8) BM220(66.2) INRA123(66.2) BMS862(67.3) HUJ246(67.9) BMS937(67.9) HUJII77(87.4) } \\
\text { BM7225(102.4) BM2924(116.5) BMC4214(123.0) }\end{array}$ & 18 \\
\hline 5 & $\begin{array}{l}\text { BMS1095(0) BM6026(6.7) BMS610(12.8) BP1(18.8) AGLA293(32.0) BMC1009(40.6) RM500(55.6) ETH10(70.0) } \\
\text { CSSM022(72.4) BMS1216(75.6) BMS1248(88.4) BM315(100.1) BMS1658(103.5) RME20(114.6) BM2830(120.2) }\end{array}$ & 15 \\
\hline 6 & ILSTS093(0) INRA133(8.2) BM1329(35.5) OARJMP36(52.4) BM415(76.3) BM4311(89.1) BM2320(120.7) BL1038(122.3) & 8 \\
\hline 7 & BM7160(0) BL1067(14.2) BMS713(15.2) DIK5321(22.3) DIK4421(22.7) DIK2207(26.7) DIK5412(30.2) & 11 \\
\hline
\end{tabular}

7 BM7160(0) BL1067(14.2) BMS713(15.2) DIK5321(22.3) DIK4421(22.7) DIK2207(26.7) DIK5412(30.2)

DIK2819(47.9) DIK4606(55.3) BM7247(58.0) UWCA20(59.9) BM6117(61.0) BMS2840(64.3) BMS2258(75.0)

OARAE129(96.6) ILSTS006(116.0) BL1043(134.1)

8 IDVGA-11(8.8) BMS1591(28.1) BMS678(38.4) INRA129(51.4) BMS2072(58.8) BMS887(60.6) URB037(61.3) MCM64(62.7) CSSM047(110.5) BMS836(114.2)

$9 \quad$ BMS2151(0) ETH225(8.1) ILSTS037(21.0) BM2504(25.2) BMS1267(33.8) UWCA9(44.9) BMS1290(59.0) BM6436(71.4) BMS2753(73.1) BMS2819(84.4) BM4208(84.6) BMS2295(91.5) BMS1967(102.5)

10 CSSM38(7.0) BMS528(19.0) BM1237(19.6) BMS2742(38.5) BMS529(48.4) BM888(50.4) TGLA433(65.8) INRA037(69.9) BMS1620(71.7) ILSTS070(72.3) BMS2641(79.1) BMS614(89.5) BMS2614(98.4)

11 BM716(9.5) BMS2569(11.7) BM2818(20.5) INRA177 2(25.7) RM096(31.3) INRA131(38.0) BM7169(41.0) BM6445(56.9) BMS1822(61.2) TGLA58(67.5) BMS2047(73.8) HUJV174(85.4) TGLA436(98.5) HEL13(114.5)

12 BMS410(0) BM6108(15.8) BM860(49.4) BMS975(61.2) BMS1316(98.7) BMS2724(105.8)

13 BMS1742(14.8) BMC1222(19.5) BM720(38.6) BM9248(52.8) BL1071(68.6) AGLA232(79.5)

14 RM180(19.1) RM011(27.7) BM4630(30.1) BM302(36.9) BMS2224(47.7) BMS108(50.8) BMS1899(52.0) BM2934(66.4) BL1036(78.7) BM6425(85.7)

15 BR3510(1.0) BMS2533(5.2) JAB8(20.8) INRA050(31.1) BMS2684(34.9) INRA145(51.6) IDVGA_10(51.7) ILSTS027(66.3) BMS812(68.8) BMS2076(75.4) BL1095(77.8) BMS820(81.6) BMS927(88.3) BMS429(93.4)

16 TGLA245(6.5) HUJ614(11.5) BM1311(30.5) TGLA53(40.6) BMS1907(46.2) BMS1207(56.5) INRA48(73.0) BM1706(80.6) MB103(87.9) BMS719(89.5) BMS462(93.2)

17 RM156(0) BMS499(3.8) BMS2220(16.2) BMS941(30.1) CSSM9(31.4) OARFCB48(41.9) BM305(51.9) ILSTS023(54.3) IDVGA 40(67.0) BM1862(86.3) BM1233(98.6)

18 IDVGA 31(0) BMS1355(2.8) BMS1322(13.8) TEXAN_10(22.7) BMS2213(26.2) INRA121(31.8) BR4406(34.8) INRA063(48.7) BM7109(49.6) ILSTS002(55.9) BMS2639(57.0) BMON117(57.1) BMS2785(73.7) BM2078(77.8) BM6507(78.9) TGLA227(84.7)

19 BM9202(0) BMS745(15.9) BP20(46.5) IDVGA_46(47.5) BMS2389(52.7) CSSM065(65.7) ETH3(81.5) BMS601(99.5)

20 BM3517(0) HEL12(0.7) BMS1282(19.1) BMS1754(24.4) TGLA126(31.2) BMS2361(45.5) AGLA29(50.6) BMS703(54.9) BM5004(64.3) UWCA26(69.8)

21 BMS1117(9.9) AGLA233(20.4) ILSTS095(24.4) BM103(30.5) IDVGA 45(31.8) INRA103(37.7) BMS2815(46.1) BM846(61.2) TGLA122(67.3) ILSTS054(71.4) BMS743(81.5) IDVGA 30(81.9)

22 CSSM26(0) INRA026(2.9) BM1558(17.3) BM3628(44.5) BMS875(61.1) BM4102(81.1)

23 CSSM5(7.2) BM47(9.1) BM1815(19.8) UWCA1(22.1) MB026(35.4) MB025(35.4) MB019(36.0) RM185(45.1) BM7233(49.1) BM1818(50.9) CSSM024(58.4) BM1905(64.3) BM1443(67.1)

24 ILSTS065(4.4) BMS2526(6.0) BM7151(6.1) BM226(6.2) TGLA351(8.6) BM7228(17.3) CSSM23(18.4) BMS2270(21.2) BMS917(25.2) BMS1862(32.8) BMS466(46.1) INRA090(53.2) BMS1926(57.4) BMS3024(62.5)

$25 \quad$ ILSTS102(6.5) BMS2843(21.2) BM737(27.8) ILSTS046(29.7) BMS1353(45.3) AF5(60.6)

26 BMS651(2.5) HEL11(20.7) BMS332(27.0) RM026(37.3) IDVGA 59(50.6) BMS882(51.0) BM804(59.6) BM9284(59.7) BM7237(64.3)

27 BMS1001(5.1) BMS2650(12.5) BMS2137(19.3) INRA16(22.0) CSSM043(34.1) IOBP313(38.0) INRA134(45.5) BM1857(52.7) BMS2116(55.4) HUJI13(56.6) BM203(64.1)

28 BMC6020(2.5) ETH1112(10.1) BL25(17.8) BMS2608(32.0) BMS1714(42.1) BMC2208(52.4)

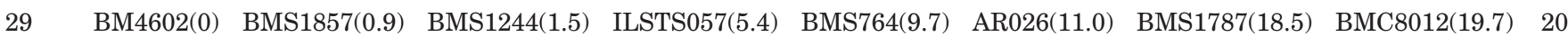
RM179(22.4) ILSTS089(22.8) RM044(23.3) BMS1600(28.4) RM040(39.9) OARHH22(41.5) BMC3224(43.6) BMS389(55.2) BMC1206(57.5) BMC6004(57.9) BMS1948(61.6) ILSTS081(65.0)

\footnotetext{
${ }^{1} \mathrm{BTA}=$ Bos taurus autosome.

${ }^{2}$ Markers are chosen from http://www.marc.usda.gov/genome/genome.html; positions of the markers are from 2004.

${ }^{3} \mathrm{NM}=$ Number of markers.
} 
marker genotypes. These phases were then assumed to be known without error. The segregation probabilities at each map position were calculated using information from all markers on the chromosome simultaneously using Haldane's map function (Haldane, 1919). Population allele frequencies at the markers were estimated using an expectation-maximization algorithm. Allele frequencies were subsequently assumed to be known without error. When it was not possible to distinguish unambiguously whether a marker allele was coming from the sire or the dam, the allele frequencies were used to calculate the segregation probabilities. Phenotypes were regressed onto the segregation probabilities. Significance thresholds were calculated using permutation tests performing 10,000 permutations (Churchill and Doerge, 1994).

Variance Component Analysis. The multivariate mixed model can be written as

$$
\boldsymbol{y}=\boldsymbol{X} \boldsymbol{\beta}+\boldsymbol{Z} \boldsymbol{u}+\sum_{i=1}^{n q t l} \boldsymbol{W}_{i} \boldsymbol{q}_{i}+\boldsymbol{e},
$$

where $\mathbf{y}$ is a $n \times t$ vector of observations on $t=\{1,2\}$ traits, $\mathbf{X}$ is a matrix relating records to the fixed effects, $\boldsymbol{\beta}$ is a vector of fixed effects, $\mathbf{Z}$ is a matrix relating records to individuals, $\mathbf{u}$ is a vector of additive polygenic effects, $\mathbf{W}$ is a matrix relating each individual's record to its QTL effect, $\mathbf{q}_{\mathbf{i}}$ is a vector of additive QTL effects corresponding to the $i$-th QTL, and $\mathbf{e}$ is a vector of residuals. The number of QTL, $n_{\mathrm{qtl}}$, is assumed to be equal to 1 or 2 . The random variables $\mathbf{u}, \mathbf{q}$, and $\mathbf{e}$ are assumed to be multivariate normally distributed and mutually uncorrelated. Specifically:

$\mathbf{u} \sim \operatorname{MVN}(\mathbf{0}, \mathbf{G})$, where $\mathbf{G}=\mathbf{G}_{\mathbf{0}} \otimes \mathbf{A}$ and

$$
\boldsymbol{G}_{0}=\left(\begin{array}{ccc}
\sigma_{g 11}^{2} & \cdots & \sigma_{g 1 t} \\
\vdots & \ddots & \vdots \\
\sigma_{g t 1} & \cdots & \sigma_{g t t}^{2}
\end{array}\right),
$$

$\mathbf{q}_{\mathbf{i}} \mid \mathrm{M}, \mathrm{p}_{\mathrm{i}} \sim \operatorname{MVN}\left(\mathbf{0}, \mathbf{K}_{\mathbf{i}}\right)$, where $\mathbf{K}_{\mathbf{i}}=\mathbf{K}_{\mathbf{0 i}} \otimes \mathbf{I B D}_{\mathbf{i} \mid \mathbf{M}, \mathbf{p i}}$ and

$$
\boldsymbol{K}_{0 i}=\left(\begin{array}{ccc}
\sigma_{q 11}^{2} & \cdots & \sigma_{q 1 t} \\
\vdots & \ddots & \vdots \\
\sigma_{q t 1} & \cdots & \sigma_{q t t}^{2}
\end{array}\right),
$$

$\mathbf{e} \sim \operatorname{MVN}(\mathbf{0}, \mathbf{R})$, where $\mathbf{R}=\mathbf{E}_{\mathbf{0}} \otimes \mathbf{I}$ and

$$
\boldsymbol{E}_{0}=\left(\begin{array}{ccc}
\sigma_{e 11}^{2} & \cdots & \sigma_{e 1 t} \\
\vdots & \ddots & \vdots \\
\sigma_{e t 1} & \cdots & \sigma_{e t t}^{2}
\end{array}\right),
$$

Above, $\mathbf{A}$ is the additive genetic relationship matrix and $\mathbf{I B D}_{\mathbf{i} \mid \mathbf{M}, \mathbf{p i}}$ is the identify by descent (IBD) matrix for the $i$ th QTL, conditional on marker data $(M)$ and the position $\left(p_{i}\right)$ of the $i$ th QTL on the chromosome.

The single trait single QTL model used for the across family analysis is equal to model [1] with $t=1$ and $\mathrm{n}_{\mathrm{qtl}}=1$ with $\mathrm{G}_{0}=\sigma_{\mathrm{a}}^{2}, \mathrm{~K}_{0}=\sigma_{\mathrm{q}}^{2}, \mathrm{E}=\sigma_{\mathrm{e}}^{2}$.

The pleiotropic model is equal to model [1] with $\mathrm{t}=$ 2 and $\mathrm{n}_{\mathrm{qtl}}=1$ with

$$
\begin{gathered}
\boldsymbol{G}_{0}=\left(\begin{array}{cc}
\sigma_{g 11}^{2} & \sigma_{g 12} \\
\sigma_{g 12} & \sigma_{g 22}^{2}
\end{array}\right), \boldsymbol{K}_{0}=\left(\begin{array}{ll}
\sigma_{q 11}^{2} & \sigma_{q 12} \\
\sigma_{q 12} & \sigma_{q 22}^{2}
\end{array}\right), \\
\text { and } \boldsymbol{E}_{0}=\left(\begin{array}{ll}
\sigma_{e 11}^{2} & \sigma_{e 12} \\
\sigma_{e 12} & \sigma_{e 22}^{2}
\end{array}\right) .
\end{gathered}
$$

The 2-trait 2-QTL model is equal to model [1] with $\mathrm{t}=2$ and $\mathrm{n}_{\mathrm{qtl}}=2$ with

$$
\begin{gathered}
\boldsymbol{G}_{0}=\left(\begin{array}{cc}
\sigma_{g 11}^{2} & \sigma_{g 12} \\
\sigma_{g 12} & \sigma_{g 22}^{2}
\end{array}\right), \boldsymbol{K}_{01}=\left(\begin{array}{cc}
\sigma_{q 11}^{2} & 0 \\
0 & 0
\end{array}\right), \\
\boldsymbol{K}_{02}=\left(\begin{array}{cc}
0 & 0 \\
0 & \sigma_{q 22}^{2}
\end{array}\right), \text { and } \boldsymbol{E}_{0}=\left(\begin{array}{cc}
\sigma_{e 11}^{2} & \sigma_{e 12} \\
\sigma_{e 12} & \sigma_{e 22}^{2}
\end{array}\right) .
\end{gathered}
$$

IBD Matrix. First, the gametic relationship matrix (Fernando and Grossman, 1989) was calculated, and then, using the linear relationship between the gametic relationship matrix and the IBD matrix, the IBD matrix was designed (George et al., 2000). The covariance structure among the random QTL allelic effects of all animals in the pedigree is described by the gametic relationship matrix. The information of the transmission of linked markers is used to calculate the IBD probabilities at the position of a putative QTL (Sørensen et al., 2003).

Significance Level. The significance level for each trait was determined by using the quick method as described by Piepho (2001). The QTL was considered to be significant when the test-statistic exceeded the 5\% chromosome-wise threshold level. To detect QTL, the chromosome was scanned and the maximum of the LR test statistics at the putative QTL position $\mathrm{p}$ (in cM) $[T(p)]$, was determined over a grid for $p$. The null hypothesis of no QTL on a given chromosome was rejected when $\max T(p)>C$. For a given critical value $C$, the chromosome-wise type I error rate was bounded above by value $\alpha$ [Formula 1, Piepho (2001)]. The upper bound in formula 1 (Piepho, 2001) is derived taking into account the fact that test statistics $T(p)$ computed at adjacent positions $\mathrm{p}$ are stochastically dependent and in fact form a stochastic process (Piepho, 2001). To de- 
termine the genome-wise threshold, the relative length of all chromosomes was taken into account using the Bonferroni inequality [Formula 4 and 5, Piepho (2001)]. A significance threshold of $5 \%$ was considered to be significant.

Model Selection. The pleiotropic model, where the QTL was assumed to affect both traits and the 2-trait2-QTL model where separate QTL affecting each trait can not be compared in the likelihood setting because these models are not nested. Therefore, the Bayes information criterion (BIC) was used to validate which model was favored (Kass and Raftery, 1995; Schwarz 1978). The formula for BIC is BIC = 2log (likelihood pleiotropic model/likelihood 2-trait-2-QTL model $)$ - $\left(\mathrm{k}_{1}\right.$ $-\mathrm{k}_{2}$ ) $\log n$, where $\mathrm{k}_{1}$ and $\mathrm{k}_{2}$ are the number of parameters to be estimated in the models and $n$ is the number of samples. The pleiotropic and the 2-trait-2-QTL model have the same number of parameters; therefore the $\mathrm{BIC}$ can be written as $\mathrm{BIC}=2[\log$ (likelihood pleiotropic model) - $\log$ (likelihood 2-trait-2-QTL model)].

A positive BIC favored the pleiotropic model, whereas a negative BIC favored the 2-trait-2-QTL model.

\section{RESULTS}

The analysis across all 19 families resulted in 25 QTL that were significant at the 5\% chromosome-wise level. The identified QTL included 2 for lameness 1, 2 for lameness2, 7 for rear legs side view, 5 for rear legs rear view, 4 for hock quality, 4 for bone quality, and 1 for foot angle (Table 2). No QTL was detected for lameness3. The QTL were spread across 20 different chromosomes, of which 5 chromosomes (BTA1, BTA11, BTA15, BTA26, and BTA27) had QTL affecting 2 different traits. None of the QTL observed had statistical significance exceeding the 5\% genome-wise threshold level. The QTL explained from 4.9 to $14.3 \%$ of the total genetic variance. For the lameness traits it was difficult to separate the QTL variance from the polygenic variance. The estimate of the polygenic variance becomes so small that the percentage of the total $\sigma_{\mathrm{g}}^{2}$ becomes $100 \%$ $\left[\% \sigma_{\text {gtotal }}^{2}=\sigma_{\text {qtl }}^{2} /\left(\sigma_{\text {qtl }}^{2}+\sigma_{\text {polygenic }}^{2}\right) \times 100 \%\right]$. Therefore, the percentage of the total $\sigma_{\mathrm{g}}^{2}$ is not mentioned. When plotting test statistics, the results of the regression method and the variance component method corresponded to each other with regard to the shape of the curve and the position of the highest peak. This result provided some confirmation of the validity of the tests. The regression analysis and the variance component analysis revealed the same QTL as being significant in the across family analysis. This result indicates that using the method of Piepho (2001) to compute the approximate threshold is an acceptable approach to obtain signifi- cance thresholds comparable with those obtained with the permutation test (Churchill and Doerge, 1994).

The regression method was used for within family analysis to identify segregating families. The number of segregating families per trait per chromosome ranged from 1 to 7 (Table 2). In several instances where 2 QTL were segregating on a single chromosome (BTA1, BTA11, BTA15, BTA26, and BTA27), different sires were segregating for the QTL. This was not the case for BTA26, where 1 QTL was segregating for lameness1 and 1 QTL for bone quality, and for BTA27, where 1 QTL was segregating for bone quality and 1 for hock quality. Two sires were segregating for only 1 of the QTL each.

To characterize the chromosomes associated with multiple QTL, a pleiotropic QTL model was applied. On BTA1 QTL were detected for both rear legs side view and rear legs rear view. On BTA11, QTL were detected for rear legs side view and hock quality. For BTA15 QTL were detected for hock quality and bone quality. On BTA27 QTL were associated with hock quality and bone quality. The positions of the QTL peaks on BTA1 and BTA11 were approximately 20 to $40 \mathrm{cM}$ apart, whereas the estimated QTL positions for the QTL on BTA15, BTA26, and BTA27 were the same. Because of difficulties in convergence, the 2-trait model revealed no extra information for the QTL on BTA1 and BTA15. For BTA11, the maximum likelihood ratio improved from approximately 6 and 7 to approximately 15 when combining rear legs side view and hock quality in a pleiotropic QTL model. The position of the pleiotropic QTL is at $10 \mathrm{cM}$ in the marker bracket flanked by BM716 and BMS2569. The correlation between effects of the QTL on rear legs side view and hock quality is 0.36 , whereas the correlation between the EBV for these traits was 0.11 . The QTL variance and the polygenic variance estimated for rear leg side view and hock quality did not differ from the corresponding variances estimated in the single trait analysis. To investigate whether this QTL was a pleiotropic QTL or 2 closely linked QTL, a 2-trait-2-QTL model was applied. This resulted likelihood ratio was 6 , meaning that $\mathrm{BIC}=9$ (15 - 6), indicating that the QTL for rear legs side view and hock quality is a single pleiotropic QTL. For BTA26, the maximum likelihood ratio increased from 6 and 9 to 17 when combining lameness 1 and bone quality in a pleiotropic QTL model. The position of the pleiotropic QTL is at $50 \mathrm{cM}$ in marker bracket RM026-IDVGA59. The correlation between the effects of the QTL on lameness 1 and bone quality is -0.49 , whereas the correlation between the EBV was -0.13. The 2-trait-2-QTL model resulted in a likelihood ratio of approximately 4 . The BIC equals 13, indicating that the QTL for lameness1 and bone quality is likely a single pleiotropic QTL. For 
Table 2. Overview of QTL obtained in the single trait analysis across families using the variance component analysis

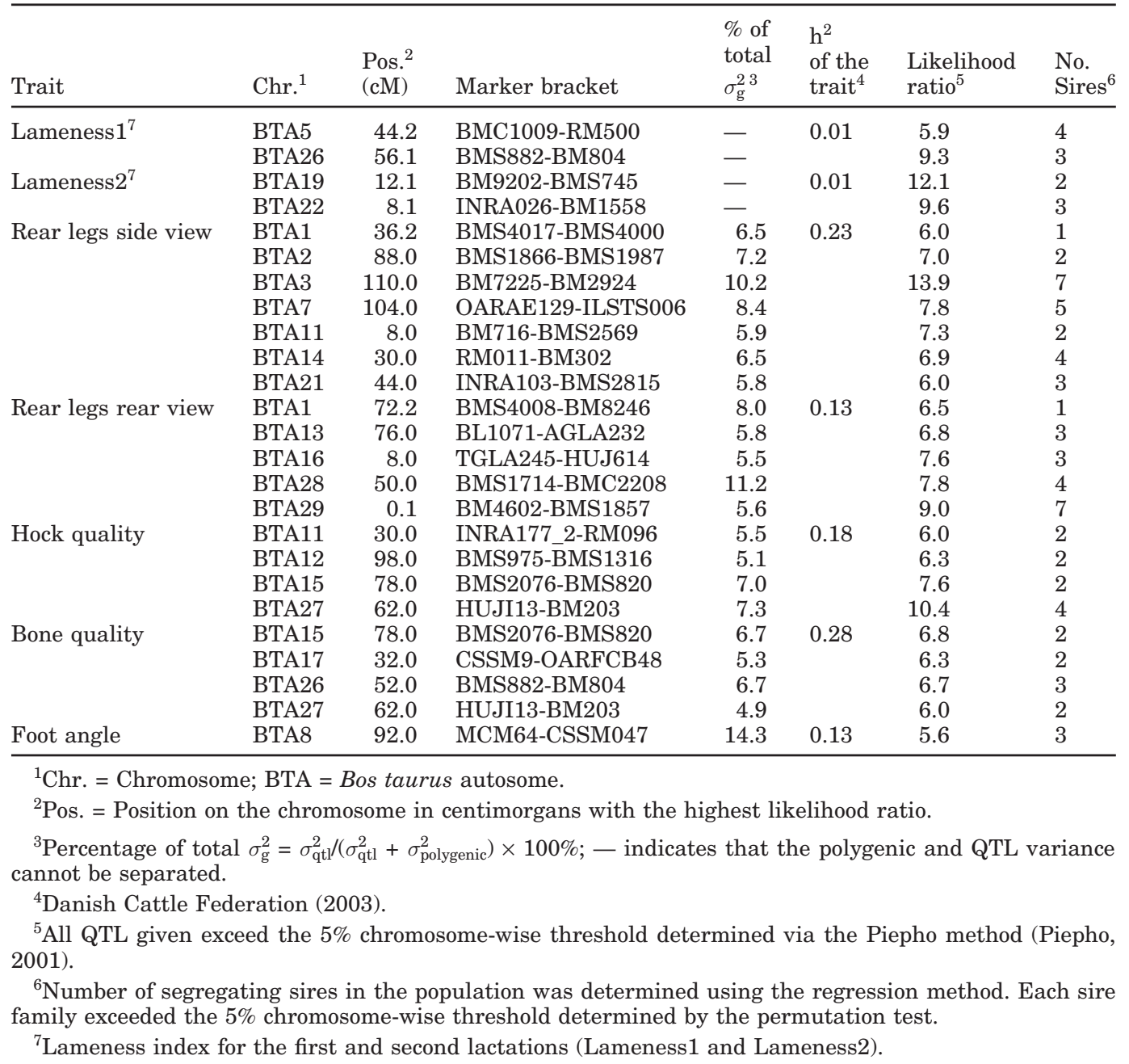

BTA27 the correlation between the effects of the QTL on rear legs rear view and hock quality was 0.49 , whereas the EBV correlation was 0.67 . However, the likelihood ratio (11) did not improve much by including hock quality and bone quality in a pleiotropic QTL model compared with the single trait analysis. The 2trait-2-QTL model resulted in a likelihood ratio of approximately 2 . The BIC was 9 , indicating that the QTL for hock quality and bone quality is more likely to be pleiotropic than 2 linked QTL. The estimated position of the pleiotropic QTL was $62 \mathrm{cM}$ in marker bracket HUJI13-BM203.

\section{DISCUSSION}

In this study we identified 25 QTL, of which 4 QTL influenced lameness and the other 21 QTL influenced leg conformation traits (Table 2). A considerable fraction of lameness is caused by claw disorders, with 25 to $30 \%$ of dairy cows treated per year, mainly during the peak lactation (Blowey and Weaver, 1991). In the Danish Holstein population claw diseases are measured in several lactations; however, this is not common practice in many other countries because measuring claw disease traits is difficult. In our study we used a lameness index that included the different claw diseases. One may argue that it would have been better to perform a QTL study based on the individual underlying traits of the index, but when underlying traits have a low incidence this is difficult. The QTL detected using the lameness index represent general QTL for lameness rather than for a specific claw-related disease trait.

van der Waaij et al. (2005) showed that various claw diseases have low correlation to leg conformation traits in Dutch dairy cattle. The lameness-indices for the 3 different lactations in this study show low correlations with the leg conformation traits. The correlations between the EBV for lameness and conformation ranged 
from 0.005 to 0.09 between lameness-indices and rear leg side view, rear leg rear view, and foot angle; and from -0.13 to -0.05 for lameness-indices and hock quality and bone quality. The correlation among EBV of the lameness-index in the different lactations is around 0.24 . These low correlations may also explain why little overlap was observed between the QTL identified for lameness and the QTL identified for the leg conformation traits as well as for the little overlap between the QTL for lameness in the different lactations. The QTL on BTA26 for Lameness1 was the only QTL showing overlap with bone quality. This QTL seemed to be pleiotropic in nature with a high correlation between traits. This result suggests that when looking for an indirect measurement to reduce lameness, selecting to increase the frequency of the superior genotype of the QTL for bone quality could reduce lameness in the first lactation.

Table 3 shows QTL associated with leg conformation traits previously reported on US Holstein cattle (Ashwell et al., 1998a,b, 2001, 2005; Schnabel et al., 2005), Dutch Holstein cattle (Schrooten et al., 2000), German Holstein cattle (Hiendleder et al., 2003), and in 3 French dairy cattle breeds: French Holstein, Normande, and Montbéliarde (Boichard et al., 2003). Comparing the results presented in Table 3 with the results of the present study (Table 2), one can see little coincidence between the QTL found in this study and the QTL presented in the literature. In this study 16 QTL were identified that had not been previously reported compared with 5 QTL that had already presented. For the trait foot angle, we only detected one QTL on BTA8, and this QTL had not been reported before. In contrast, QTL associated with foot angle were more abundant in the German Holstein population (5 QTL detected on BTA5, BTA6, BTA17, BTA21, and BTA23; Hiendleder et al., 2003) and the US Holstein population (11 QTL detected on BTA6, BTA7, BTA9, BTA12, BTA13, BTA14, BTA16, BTA17, BTA18, BTA22, BTA23, BTA25, BTA28, and BTA29; Ashwell et al., 1998a,b, 2001, 2005; Schnabel et al., 2005).

Great care should be exercised before excluding the possibility of QTL identified in different studies being identical. This is because there are differences in the marker maps used, and usually confidence intervals are large. Therefore, we only make the comparison when the flanking markers are mapped in both populations.

BTA14 was previously reported to harbor a QTL associated with rear leg side view (Ashwell et al., 1998b) near marker BM6425. This marker is approximately $50 \mathrm{cM}$ from the marker interval RM011 to BM4630, in which a QTL was detected for rear leg side view in our study. Within family analysis of the Danish Holstein population did not show any significant QTL near marker BM6425; therefore, it is not likely that these QTL are caused by variation of the same genes. The chromosomes BTA3, BTA7, BTA11, and BTA21 were reported earlier to harbor QTL related to leg traits but not for the trait rear legs side view, as in our study. In addition, our study revealed QTL for rear leg side view on 2 chromosomes that had not been reported earlier to have QTL for leg related traits.

For the trait rear legs rear view, 5 QTL were detected in the current study. Of these, 2 had not been reported earlier (BTA1 and BTA29), whereas BTA13, BTA16, and BTA28 were previously reported to harbor a QTL associated with rear leg rear view (Hiendleder et al., 2003; Ashwell et al., 2005). Currently the marker compatibility between the studies for BTA13 is not very good. In a next step adding markers used in Hiendleder et al. (2003) could help to validate whether the QTL for rear legs rear view segregating in both populations are the same.

The QTL detected for hock quality were located on 4 different chromosomes (BTA11, BTA12, BTA15, and BTA27). Hiendleder et al. (2003) reported 3 chromosomes with a QTL for hocks (BTA11, BTA13, and BTA21). The map distances between the markers on BTA11 in Hiendleder et al. (2003) and in our study are very similar. It would be interesting to add marker INRA032 for a fair comparison; however, in our study there are no sire families segregating for hock quality in the area between markers BM6445 and HEL13. This result may be due to the fact that not all sires were equally typed in that area. The other QTL detected in our study were on chromosomes (BTA12, BTA15, and BTA27) not previously reported to contain QTL associated with hock quality. However, QTL on BTA12 and BTA27 have been reported previously for other legrelated traits (Ashwell et al., 1998b, 2001). To identify whether the QTL detected for the same trait are identical between breeds, a combined analysis of the data of the different independent studies could potentially lead to more precise estimates of the effects and locations of a common QTL and could be used to examine differences in QTL effects in different populations (Walling et al., 2000).

The QTL identified for bone quality on BTA15, BTA17, BTA26, and BTA27 have not been reported before. Interestingly, the QTL on BTA15 for bone quality is in the same marker bracket as the QTL associated with hock quality, as well as the QTL on BTA27. The characterization of the QTL on BTA15 did not reveal additional information because the model did not converge. To characterize the QTL on BTA27 a 2-trait QTL analysis revealed a moderate correlation on the EBV level and a weak correlation on the QTL level. In the 
Table 3. Results from studies on detection of QTL associated with leg conformation traits

\begin{tabular}{|c|c|c|c|c|c|}
\hline Chr. $^{1}$ & Trait & $\begin{array}{l}\text { Marker/Marker } \\
\text { bracket }\end{array}$ & Position $^{2}$ & Position $^{3}$ & Study $^{4}$ \\
\hline BTA3 & Foot angle & BM4301-HUJI177 & 65 & 82.7-NA & $\mathrm{D}$ \\
\hline BTA5 & Foot angle & Lysmic-ETH10 & 72 & NA-71.8 & $\mathrm{G} / \mathrm{H}$ \\
\hline \multirow[t]{3}{*}{ BTA6 } & Foot angle & FBN14 & 88 & & $\mathrm{G} / \mathrm{H}$ \\
\hline & Foot angle & BM4322-BMS470 & 67 & $63.9-67.4$ & $\mathrm{D}$ \\
\hline & Rear leg set & BP7 & 85 & 98.5 & $\mathrm{E}$ \\
\hline \multirow{4}{*}{ BTA7 } & Feet and leg score & BM2707 & & NA & B \\
\hline & Foot angle & BB719-BM9065 & 83 & $83.5-101.1$ & $\mathrm{D}$ \\
\hline & Feet and leg score & BMS2072-IDVGA52 & 62 & NA-NA & I \\
\hline & Rear leg rear view & BM711-CSSM47 & & $92.7-118.7$ & I \\
\hline \multirow[t]{4}{*}{ BTA9 } & Heel depth & BM2504 & 32 & 30.9 & $\mathrm{~F}$ \\
\hline & Foot angle & BM4204 & & 55.4 & A \\
\hline & Rear leg side view & URB024-TGLA73 & 61 & $77.6-98.2$ & $\mathrm{D}$ \\
\hline & Feet and legs & BM4204 & & 55.4 & A \\
\hline \multirow[t]{2}{*}{ BTA11 } & Hocks & INRA032 & 61 & 68.7 & $\mathrm{G} / \mathrm{H}$ \\
\hline & Rear leg set rear view & INRA032 & 61 & 68.7 & $\mathrm{G} / \mathrm{H}$ \\
\hline \multirow[t]{4}{*}{ BTA12 } & Foot angle & BM6404 & & 57.1 & $\mathrm{C}$ \\
\hline & Feet and leg composite & BM6404 & & 57.1 & $\mathrm{C}$ \\
\hline & Rear legs rear view & BM6404 & & 57.1 & $\mathrm{C}$ \\
\hline & Rear legs rear view & BM6404-BMS975 & 41 & $57.1-63.8$ & $\mathrm{D}$ \\
\hline \multirow[t]{3}{*}{ BTA13 } & Hocks & MILSTS077 & 53 & 39.6 & $\mathrm{G} / \mathrm{H}$ \\
\hline & Rear leg set rear view & MILSTS077 & 54 & 39.6 & $\mathrm{G} / \mathrm{H}$ \\
\hline & Foot angle & UWCA25-BL42 & 54 & $59.2-69.8$ & $\mathrm{D}$ \\
\hline \multirow[t]{2}{*}{ BTA14 } & Rear leg side view & BM6425 & & 95.1 & B \\
\hline & Foot angle & BMS1899-BM4513 & 54 & $69.0-79.8$ & $\mathrm{D}$ \\
\hline \multirow[t]{4}{*}{ BTA16 } & Feet and legs CI & BM719 & & 77.5 & B \\
\hline & Rear leg side view & BM719 & & 77.5 & B \\
\hline & Rear leg rear view & Centro-BM6430 & 0 & 8.5 & $\mathrm{D}$ \\
\hline & Foot angle & BM719 & & 77.6 & B \\
\hline \multirow[t]{3}{*}{ BTA17 } & Foot angle & RM156-BMS2220 & 5 & $2.4-17.3$ & $\mathrm{G} / \mathrm{H}$ \\
\hline & Foot angle & BM8125 & & 66.5 & B \\
\hline & Rear leg view & BM8125 & & 66.5 & $\mathrm{~B}$ \\
\hline \multirow[t]{2}{*}{ BTA18 } & Heel depth & ILSTS002 & 74 & 54.7 & $\mathrm{~F}$ \\
\hline & Foot angle & BMS929-BM6507 & & $61.2-78.8$ & I \\
\hline BTA19 & Rear leg set & BM17132 & 76 & 59.2 & $\mathrm{E}$ \\
\hline \multirow[t]{3}{*}{ BTA21 } & Foot angle & BM8115-HEL5 & 6 & $0-13.5$ & $\mathrm{G} / \mathrm{H}$ \\
\hline & Hocks & HEL5 & 12 & 13.5 & $\mathrm{G} / \mathrm{H}$ \\
\hline & Rear leg set rear view & HEL5 & 12 & 13.5 & $\mathrm{G} / \mathrm{H}$ \\
\hline \multirow{3}{*}{ BTA22 } & Foot angle & BM3628 & & 47.1 & A \\
\hline & Feet and leg score & BM3628 & & 47.1 & A \\
\hline & Feet and legs CI & BM3628 & & 47.1 & A \\
\hline \multirow[t]{3}{*}{ BTA23 } & Foot angle & KIEL_E7-BM1443 & 84 & NA-73.8 & $\mathrm{G} / \mathrm{H}$ \\
\hline & Foot angle & BM1905 & & 71.6 & A \\
\hline & Rear legs rear view & CYP21 & & 42.7 & A \\
\hline \multirow{3}{*}{ BTA24 } & Rear leg set & AGLA269 & 17 & 30.5 & $\mathrm{E}$ \\
\hline & Foot diagonal & AGLA269 & 17 & 30.5 & $\mathrm{E}$ \\
\hline & Feet and legs & CSSM31-AGLA269 & 15 & $25.8-30.5$ & $\mathrm{E}$ \\
\hline BTA25 & Foot angle & BMS1353-BM1864 & 39 & $46.4-68.4$ & $\mathrm{D}$ \\
\hline \multirow[t]{2}{*}{ BTA27 } & Feet and legs CI & BM3507 & & 0 & B \\
\hline & Rear leg side view & BM3507 & & 0 & $\mathrm{~B}$ \\
\hline \multirow[t]{2}{*}{ BTA28 } & Foot angle & BM6544-BM2515 & 48 & NA-57.7 & $\mathrm{D}$ \\
\hline & Rear leg rear view & BL25-BM6466 & 26 & $24.8-42.9$ & $\mathrm{D}$ \\
\hline BTA29 & Foot angle & BMS3224-BMC6004 & 34 & NA-62.3 & $\mathrm{D}$ \\
\hline
\end{tabular}

${ }^{1}$ Chr. $=$ Chromosome; BTA $=$ Bos taurus autosome

${ }^{2}$ Position = Position on the marker map used in the study in which the QTL was detected.

${ }^{3}$ Position = Position on the MARC consensus marker map. NA = marker information not available.

${ }^{4} \mathrm{~A}=$ Ashwell et al. (1998a); B = Ashwell et al. (1998b); C = Ashwell et al. (2001); D = Ashwell et al. (2005); $\mathrm{E}=$ Schrooten et al. (2000); F = Boichard et al. (2003); G = Hiendleder et al. (2003); H = Thomsen et al. (2000), reports the map distances of the markers; I = Schnabel et al. (2005).

case of a biallelic QTL, one would expect a genetic correlation very close to +1 or -1 . In addition, the sires segregating for these 2 QTL on BTA27 were not the same sires. These results suggest no pleiotropic QTL but rather 2 distinct QTL, each affecting 1 trait. The use of pleiotropic QTL with an advantageous effect on each trait would be interesting in case one would like to select for both traits at the same time; however, when 
the effects are of antagonistic sign, selection is difficult using a pleiotropic QTL because the positive effect of the QTL for one trait is negative for another trait.

In this study we presented QTL associated with lameness and leg conformation traits using a moderately dense marker map for a genome scan. The QTL detected for lameness were distinct between lactations. The QTL for lameness showed little overlap with the QTL found for leg conformation traits, except for bone quality. The QTL detected for leg conformation traits in the Danish Holstein population showed little overlap with the previously published QTL for feet and leg traits; however, analysis of the same markers across populations in the various studies is necessary for full informative comparison of the results. In a next step, the method of combining linkage and linkage disequilibrium (Meuwissen et al., 2002) could be used to obtain a more precise estimate of the QTL position. Together with the genomic information becoming available on gene location (Itoh et al., 2005), this strategy will provide information on potential useful markers for marker-assisted selection for lameness.

\section{ACKNOWLEDGMENTS}

This project was funded by FREM98 DJF: New technologies in farm animal breeding and j.no. 34016503 136: DNA-based selection to improve disease resistance, fertility, calf survival, and production in Danish dairy cattle from the Danish Directorate for Food, Fisheries, and Agri Business. The reviewers are kindly acknowledged for their helpful suggestions.

\section{REFERENCES}

APHIS (Animal and Plant Health Inspection Service). 1996. Part 1. Reference of 1996 Dairy Management Practices. National Animal Health Monitoring System. USDA, Fort Collins, CO.

Ashwell, M. S., Y. Da, P. M. VanRaden, C. E. Rexroad, Jr., and R. H. Miller. 1998a. Detection of putative loci affecting conformational type traits in an elite population of United States Holsteins using microsatellite markers. J. Dairy Sci. 81:1120-1125.

Ashwell, M. S., Y. Da, C. P. van Tassell, P. M. VanRaden, R. H. Miller, and C. E. Rexroad, Jr. 1998b. Detection of putative loci affecting milk production and composition, health, and type traits in a United States Holstein population. J. Dairy Sci. 81:33093314 .

Ashwell, M. S., D. W. Heyen, J. I. Weller, M. Ron, T. S. Sonstegard, C. P. van Tassell, and H. A. Lewin. 2005. Detection of quantitative trait loci influencing conformation traits and calving ease in Holstein-Friesian cattle. J. Dairy Sci. 88:4111-4119.

Ashwell, M. S., C. P. van Tassell, and T. S. Sonstegard. 2001. A genome scan to identify quantitative trait loci affecting economically important traits in a US Holstein population. J. Dairy Sci. 84:2535-2542.

Barendse, W., D. Vaiman, S. J. Kemp, Y. Sugimoto, S. M. Armitage, J. L. Williams, H. S. Sun, A. Eggen, M. Agaba, S. A. Aleyasin, M. Band, M. D. Bishop, J. Buitkamp, K. Byrne, F. Collins, L. Cooper, W. Coppieters, B. Denys, R. D. Drinkwater, K. Easterday, C. Elduque, S. Ennis, G. Erhardt, L. Ferretti, N. Flavin, Q. Gao,
M. Georges, R. Gurung, B. Harlizius, G. Hawkins, J. Hetzel, T. Hirano, D. Hulme, C. Jorgensen, M. Keßler, B. W. Kirkpatrick, B. Konfortov, S. Kostia, C. Kühn, J. A. Lenstra, H. Leveziel, H. A. Lewin, B. Leyhe, L. Lil, I. Martin Burriel, R. A. McGraw, J. R. Miller, D. E. Moody, S. S. Moore, S. Nakane, I. J. Nijman, I. Olsaker, D. Pomp, A. Rando, M. Ron, A. Shalom, A. J. Teale, U. Thieven, B. G. D. Urquhart, D. I. Vage, A. Van de Weghe, S. Varvio, R. Velmala, J. Vilkki, R. Weikard, C. Woodside, J. E. Womack, M. Zanotti, and P. Zaragoza. 1997. A medium density genetic linkage map of the bovine genome. Mamm. Genome 8:21-28.

Blowey, R. W., and A. D. Weaver. 1991. Pages 89-128 in Diseases and Disorders of Cattle. Wolfe Publishing Ltd., Aylesbury, UK.

Boelling, D., P. Madsen, and J. Jensen. 2001. Genetic parameters of foot and leg traits in future AI bulls. II. Correlation to body conformation traits in daughters. Acta Agric. Scand. Anim. Sci. 51:122-128.

Boichard, D., C. Grohs, F. Bourgeois, F. Cerqueira, R. Faugeras, A. Neau, R. Rupp, Y. Amigues, M. Y. Boscher, and H. Levéziel. 2003. Detection of genes influencing economic traits in three French dairy cattle breeds. Genet. Sel. Evol. 35:77-101.

Bovenhuis, H., and C. Schrooten. 2002. Quantitative trait loci for milk production traits in dairy cattle. Proc. 7th WCGALP, Montpellier, France 31:27-34.

Churchill, G. A., and R. W. Doerge. 1994. Empirical threshold values for quantitative trait mapping. Genetics 138:963-971.

Danish Cattle Federation. 2003. Principles of Danish Cattle breeding, 7th ed. Online. http://www.lr.dk/kvaeg/diverse/principles.pdf Accessed Jan. 15, 2005.

Enting, H., D. Kooij, A. A. Dijkhuizen, R. B. M. Huirne, and E. N. Noordhuizen-Stassen. 1997. Economic losses due to clinical lameness in dairy cattle. Livest. Prod. Sci. 49:259-267.

Fernando, R. L., and M. Grossman. 1989. Marker assisted selection using best linear unbiased prediction. Genet. Sel. Evol. $21: 467-477$.

George, A. W., P. M. Visscher, and C. S. Haley. 2000. Mapping quantitative trait loci in complex pedigrees: A two-step variance component approach. Genetics 156:2081-2092.

Haldane, J. B. S. 1919. The combination of linkage values and the calculation of distances between the loci of linked factors. J. Genet. 8:299-309.

Hiendleder, S., H. Thomsen, N. Reinsch, J. Bennewitz, B. LeyheHorn, C. Looft, N. Xu, I. Medjugorac, I. Russ, C. Kühn, G. A. Brockmann, J. Blümel, B. Brenig, F. Reinhardt, R. Reents, G. Averdunk, M. Schwerin, M. Förster, E. Kalm, and G. Erhardt. 2003. Mapping of QTL for body conformation and behavior in cattle. J. Hered. 94:496-506.

Holmberg, M., and L. Andersson-Eklund. 2004. Quantitative trait loci affecting health traits in Swedish dairy cattle. J. Dairy Sci. 87:2653-2659.

Itoh, T., T. Watanabe, N. Ihara, P. Mariani, C. W. Beattie, Y. Sugimoto, and A. Takasuga. 2005. A comprehensive radiation hybrid map of the bovine genome comprising 5593 loci. Genomics $85: 413-424$.

Kass, R. E., and A. E. Raftery. 1995. Bayes factors. J. Am. Stat. Assoc. 90:773-795.

Kühn, C., J. Bennewitz, N. Reinsch, N. Xu, H. Thomsen, C. Looft, G. A. Brockmann, M. Schwerin, C. Weimann, S. Hiendleder, G. Erhardt, I. Medjugorac, M. Förster, B. Brenig, F. Reinhardt, R. Reents, I. Russ, G. Averdunk, J. Blümel, and E. Kalm. 2003. Quantitative trait loci mapping for functional traits in the German Holstein cattle population. J. Dairy Sci. 86:360-368.

McDaniel, B. T. 1997. Breeding programs to reduce foot and leg problems. Proc. Int. Workshop on Genetic Improvement of Functional Traits in Cattle; Health. Interbull Bull. No. 15:115-122.

Meuwissen, T. H. E., A. Karlsen, S. Lien, I. Olsaker, and M. E. Goddard. 2002. Fine mapping of a quantitative trait locus for twinning rate using combined linkage and linkage disequilibrium mapping. Genetics 161:373-379.

Pedersen Aamand, G. 2002. Årsstatistik Avl 2001 2002. Rapport nr. 101. Landbrugets Rådbrugetscenter Dansk Kvæg. 12-13. 
Pérez-Cabal, M. A., and R. Alenda. 2002. Genetic relationships between lifetime profit and type traits in Spanish Holstein cows. J. Dairy Sci. 85:3480-3491.

Piepho, H.-P. 2001. A quick method for computing approximate thresholds for quantitative trait loci detection. Genetics 157:425-432.

Schmutz, S. M., J. M. Stookey, D. C. Winkelman Sim, C. S. Waltz, Y. Plante, and F. C. Buchanan. 2001. A QTL study of cattle behavioural traits in embryo transfer families. J. Hered. 92:290-292.

Schnabel, R. D., T. S. Sonstegard, J. F. Taylor, and M. S. Ashwell. 2005. Whole-genome scan to detect QTL for milk production, fertility, and functional traits in two US Holstein families. Anim. Genet. 36:408-416.

Schrooten, C., H. Bovenhuis, W. Coppieters, and J. A. M. Van Arendonk. 2000. Whole genome scan to detect quantitative trait loci for conformation and functional traits in dairy cattle. J. Dairy Sci. 83:795-806.

Schwarz, G. 1978. Estimating the dimensions of a model. Ann. Statist. 6:461-464.

Smit, H., B. Verbeek, D. J. Peterse, J. Jansen, B. T. McDaniel, and R. D. Politiek. 1986. Genetic aspects of claw disorders, claw measurements and 'type' scores for feet in Friesian cattle. Livest. Prod. Sci. 15:205.
Sørensen, P., M. S. Lund, B. Guldbrandtsen, J. Jensen, and D. Sorensen. 2003. A comparison of bivariate and univariate QTL mapping in livestock populations. Genet. Sel. Evol. 35:605-622.

Thomsen, P. T., A. M. Kjeldsen, J. T. Sørensen, and H. Houe. 2004. Mortality (including euthanasia) among Danish dairy cows (19902001). Prev. Vet. Med. 62:19-33.

Thomsen, H., N. Reinsch, N. Xu, C. Looft, S. Grupe, C. Kühn, G A. Brockmann, M. Schwerin, B. Leyhe-Horn, S. Hiendleder, G. Erhardt, I. Medjugorac, I. Russ, M. Förster, B. Brenig, F. Reinhardt, R. Reents, J. Blümel, G. Averdunk, and E. Kalm. 2000. A male bovine linkage map for the ADR granddaughter design. J. Anim. Breed. Genet. 117:289-306.

van der Waaij, E. H., M. Holzhauer, E. Ellen, C. Kamphuis, and G. De Jong. 2005. Genetic parameters for claw disorders in Dutch dairy cattle and correlations with conformation traits. J. Dairy Sci. 88:3672-3678.

Van Dorp, T. E., J. C. M. Dekkers, S. W. Martin, and J. P. T. M. Noordhuizen. 1998. Genetic parameters of health disorders, and relationships with 305-day milk yield and conformation traits of registered Holstein cows. J. Dairy Sci. 81:2264-2270.

Walling, G. A., P. M. Visscher, L. Andersson, M. F. Rothschild, L. Wang, G. Moser, M. A. M. Groenen, J.-P. Binadel, S. Cepica, A. L. Archibald, H. Geldermann, D. J. de Koning, D. Milan, and C. S. Haley. 2000. Combined analysis of data from quantitative trait loci mapping studies: Chromosome 4 effects on porcine growth and fatness. Genetics 155:1369-1378. 